\title{
Self-assembled Dual Helical Nanofibers of Amphiphilic Perylene Diimides with Oligopeptide Substituted
}

Duo Wei*[a,b], Lingling Ge ${ }^{[a]}$, Zhifeng Wang ${ }^{[a]}$, Yuyang Wang ${ }^{[b]}$, Rong Guo*[a]

[a] Dr. D. Wei, Dr. L. Ge, Prof. R. Guo, School of Chemistry and Chemical Engineering Yangzhou University, Yangzhou 225009 (China) [b] Dr. D. Wei, Dr. Z. Wang, Dr. Y. Wang, Testing center, Yangzhou University, Yangzhou 225009 (China)

\section{Supporting Information}

\section{Table of Contents}

$\begin{array}{ll}\text { Experimental details } & \text { S2 }\end{array}$

$\begin{array}{ll}\text { Synthetic route } & \text { S3 }\end{array}$

$\begin{array}{lr}\text { Supporting Figures and Table } & \text { S4 }\end{array}$ 


\section{Experimental details}

The MALDI-TOF MS analysis were recorded using AB SCIEX TOF/TOFTM 5800 (Applied Biosystem, Foster city, USA) equipped with a Nd:YAG laser (349 nm). The matrix solution was prepared by dissolving $\alpha$-cyano-4-hydroxycinnamic acid (CHCA) in $\mathrm{ACN} /$ water $(50: 50 \mathrm{v} / \mathrm{v})$ with $0.1 \%$ TFA at a concentration of $10 \mathrm{mg} / \mathrm{ml}$. A drop of the matrix solution was loaded on the MALDI-TOF plate and allowed to dry under room temperature $\left(\sim 22^{\circ} \mathrm{C}\right)$, and then a drop of the sample liquid was loaded on the top of the matrix and dried. The spectra were obtained in positive reflector ion mode in a 500-2000 Da molecular weight range. 


\section{Synthetic route}
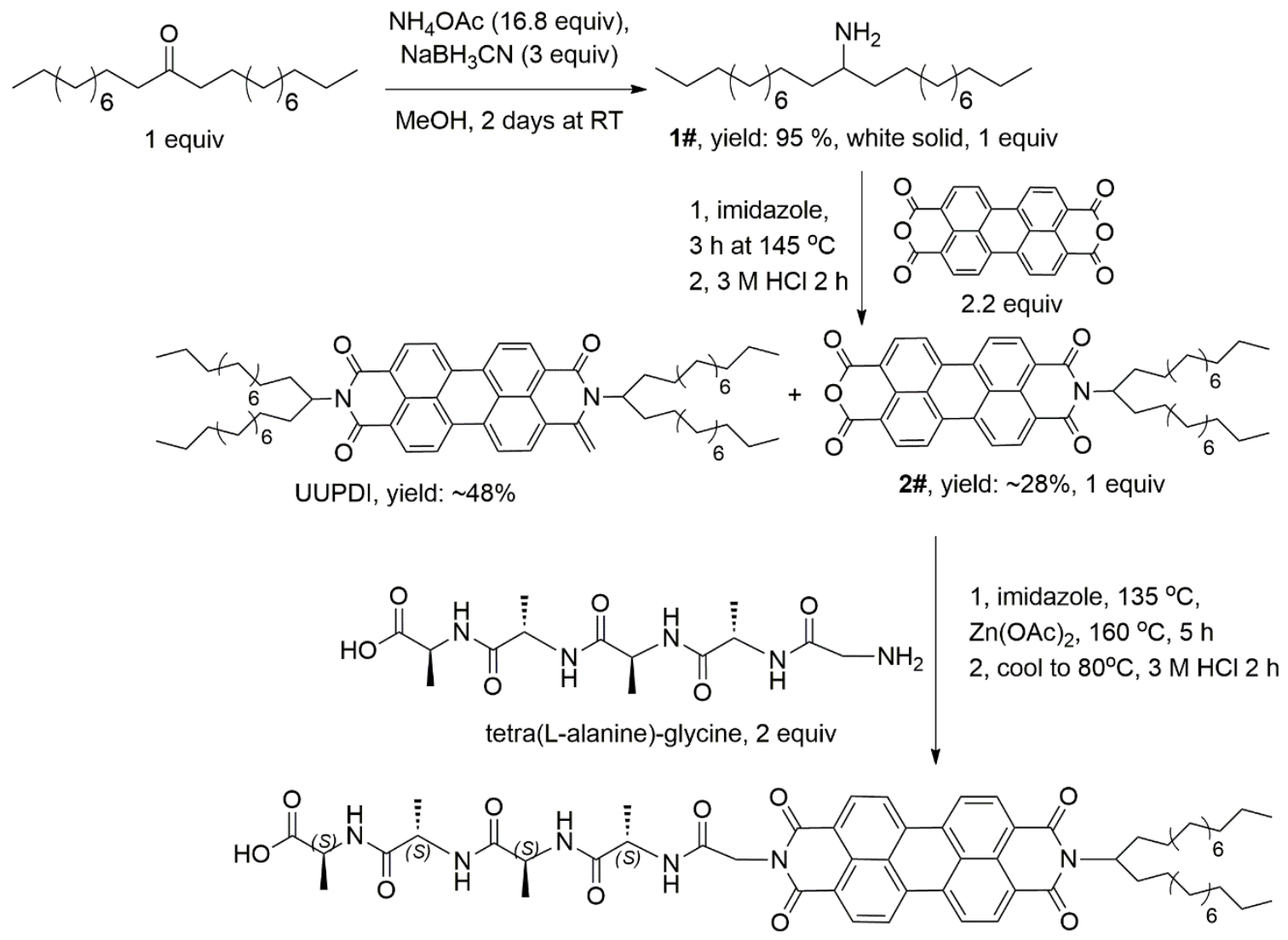

AUPDI, yield: $66.6 \%$

Scheme S1. Synthesis route of perylene diimide (PDI) derivatives: UUPDI and AUPDI. 


\section{Supporting Figures}

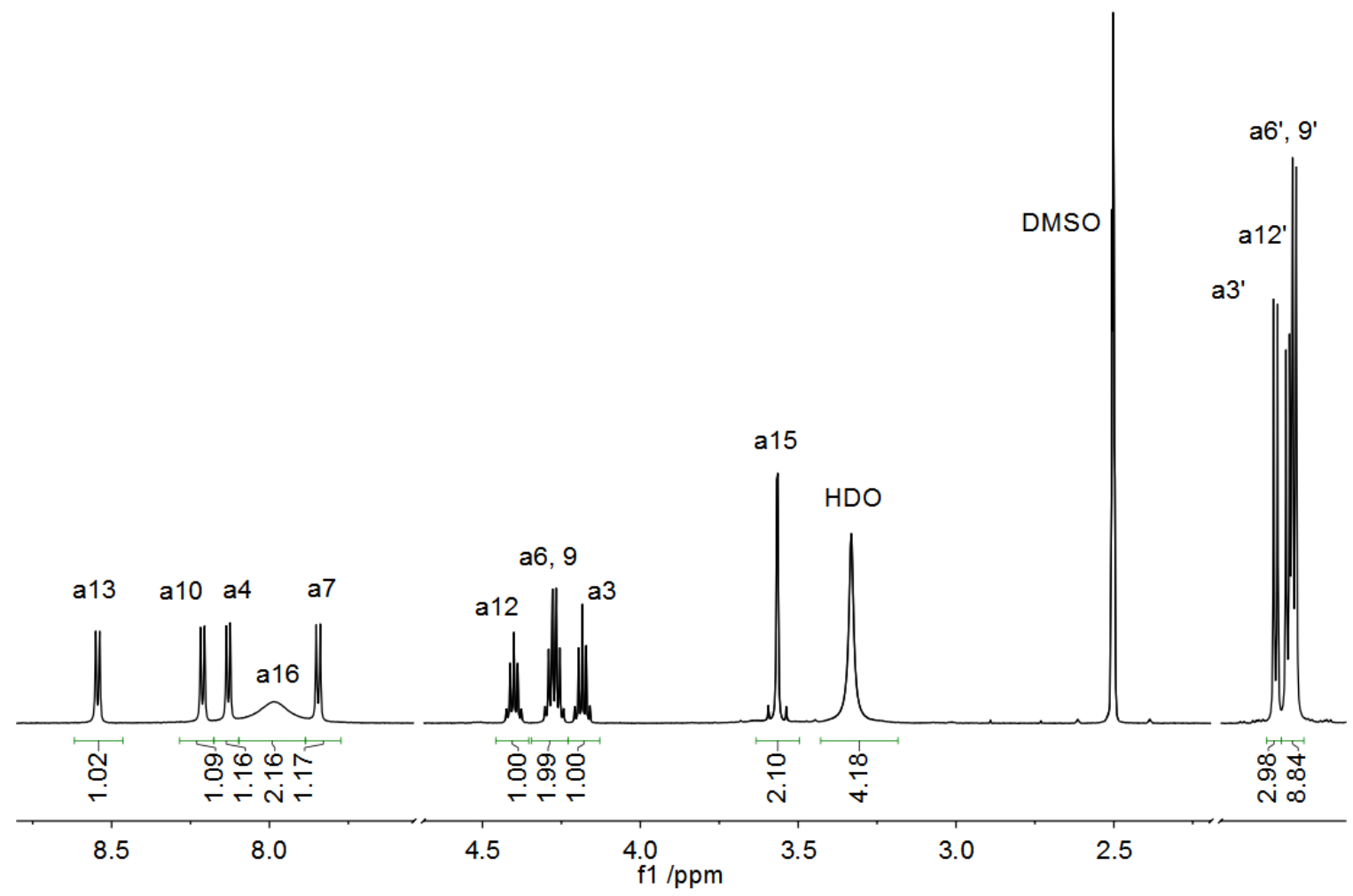

Figure S1. ${ }^{1} \mathrm{H}$ NMR spectrum of L-alanine-glycine in DMSO-d. The assignment of each proton is marked. 

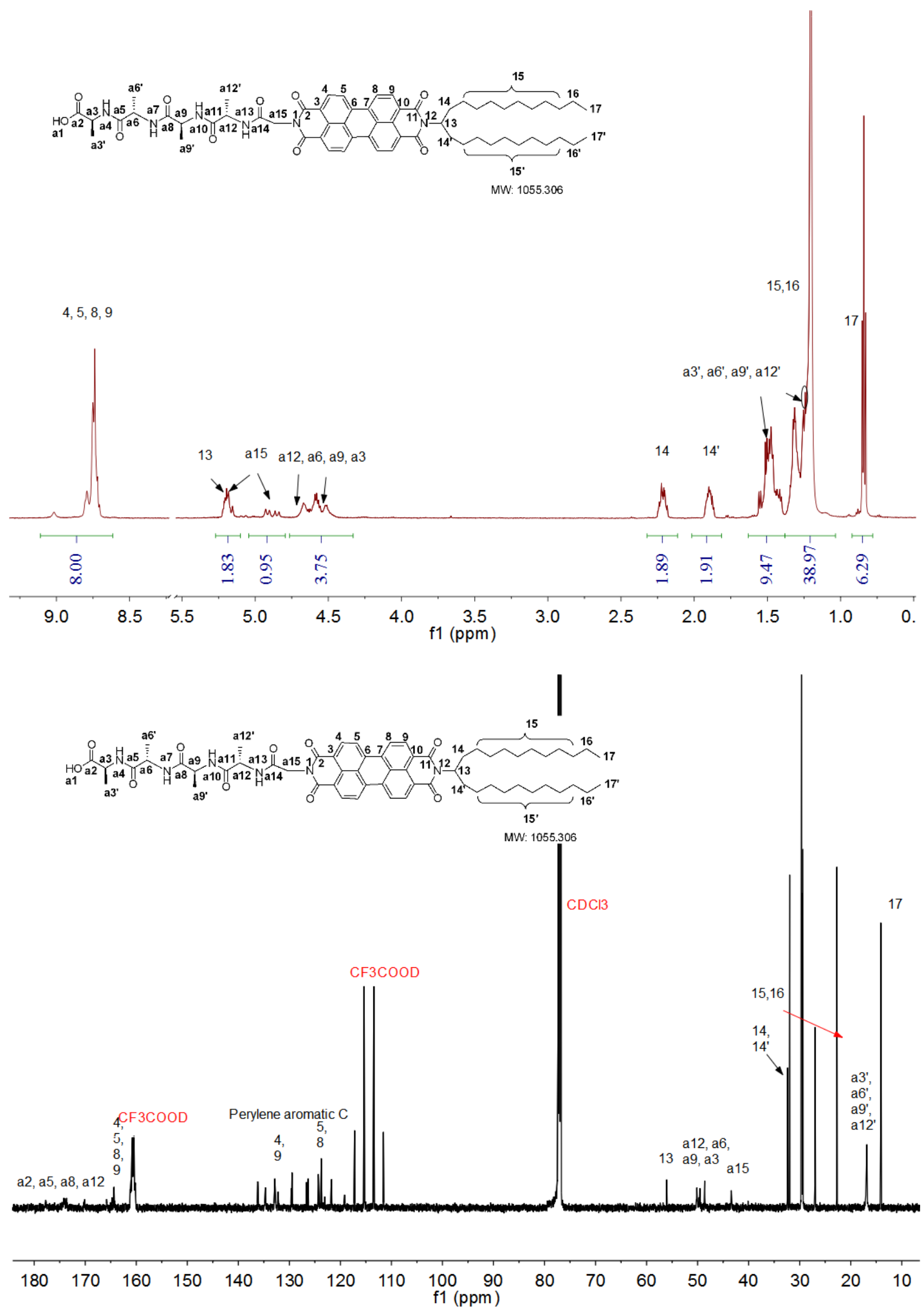

Figure S2. ${ }^{1} \mathrm{H}$ and ${ }^{13} \mathrm{C}$ NMR spectra of AUPDI in $\mathrm{CDCl}_{3}$ in the presence of TFA-d. The assignment is marked. 

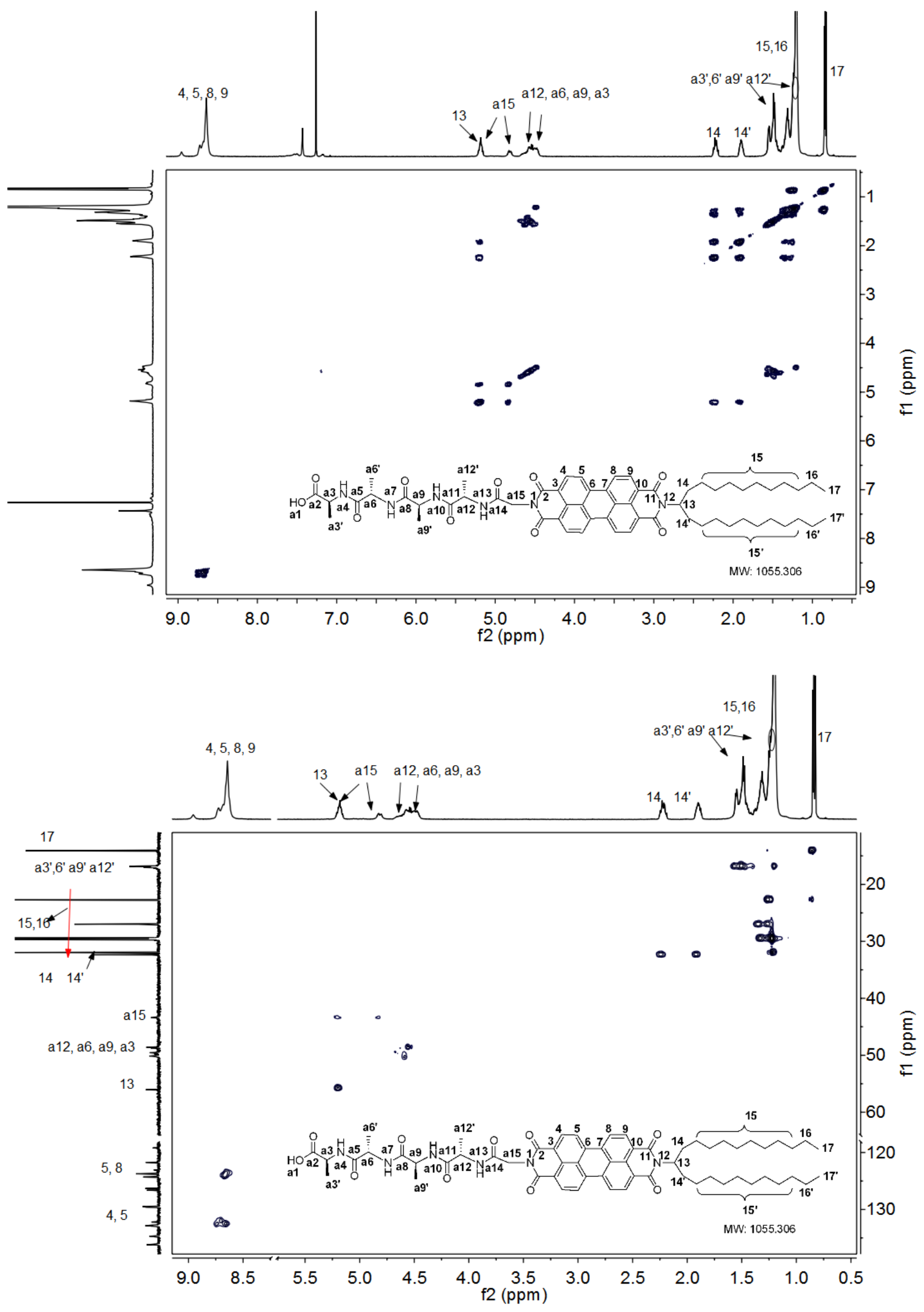

Figure S3. COSY and HSQC spectra of AUPDI in $\mathrm{CDCl}_{3}$ with $10 \mu \mathrm{L}$ TFA-d. 


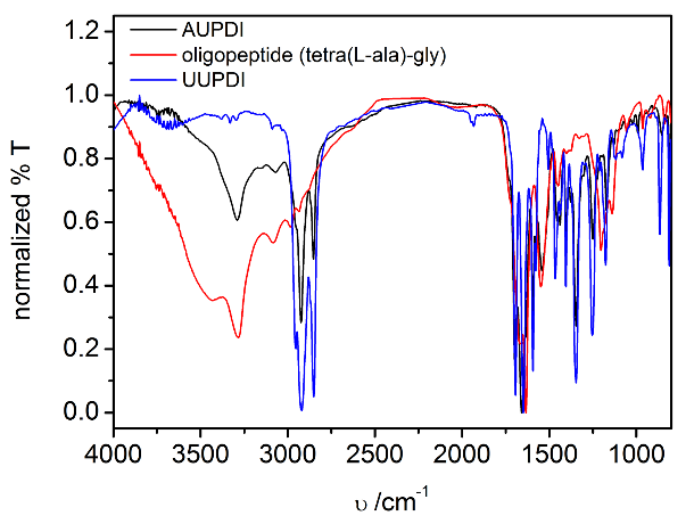

Figure S4. IR spectra of AUPDI, UUPDI and the oligopeptide block powders.

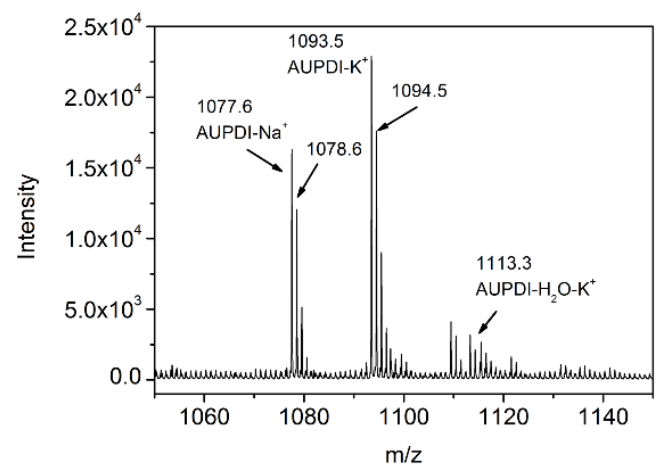

Figure S5. MALDI-TOF mass spectrum of AUPDI.
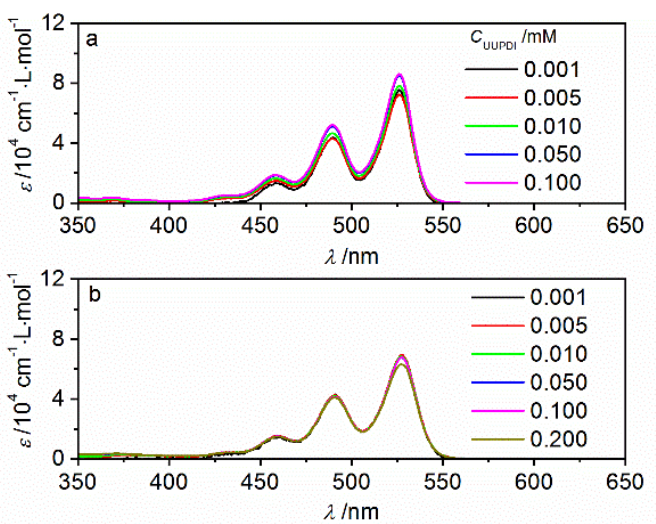

Figure S6. UV-Vis spectra of UUPDI as a function of concentration in chloroform (a) and in p-xylene (b) 


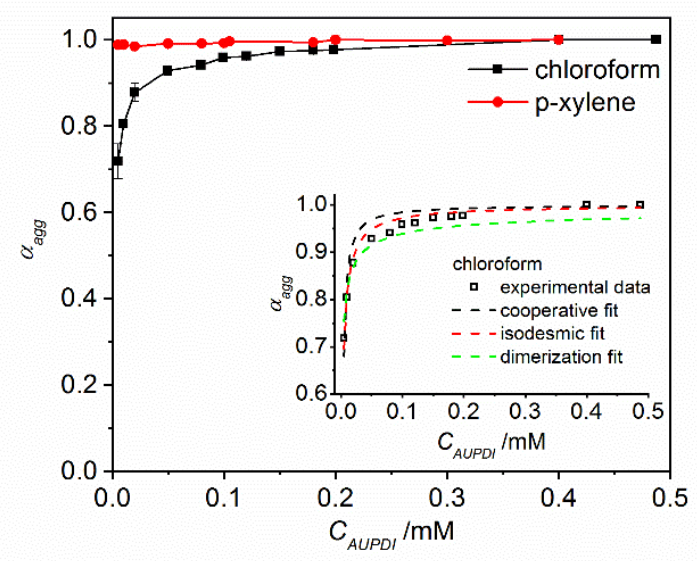

Figure S7. the aggregation degree $\left(\alpha_{a g g}\right)$ as a function of AUPDI concentration in chloroform and p-xylene. The aggregation degree $\left(\alpha_{a g g}\right)$ was calculated according to $\left[\varepsilon_{i^{-}}\right.$ $\left.\varepsilon_{m o n}\right] /\left[\varepsilon_{a g g}-\varepsilon_{m o n}\right]$, where $\varepsilon_{m o n}$ denotes the $\varepsilon$ at $526 \mathrm{~nm}$ (chloroform) or $527 \mathrm{~nm}$ (p-xylene) of the nonaggregated reference UUPDI at $0.010 \mathrm{mM}$, and $\varepsilon_{i}$ and $\varepsilon_{a g g}$ represent $\varepsilon$ of the sample at different concentrations and the highest concentration investigated, respectively. The inset represents the fitting results based on different aggregation mechanisms for the chloroform case.
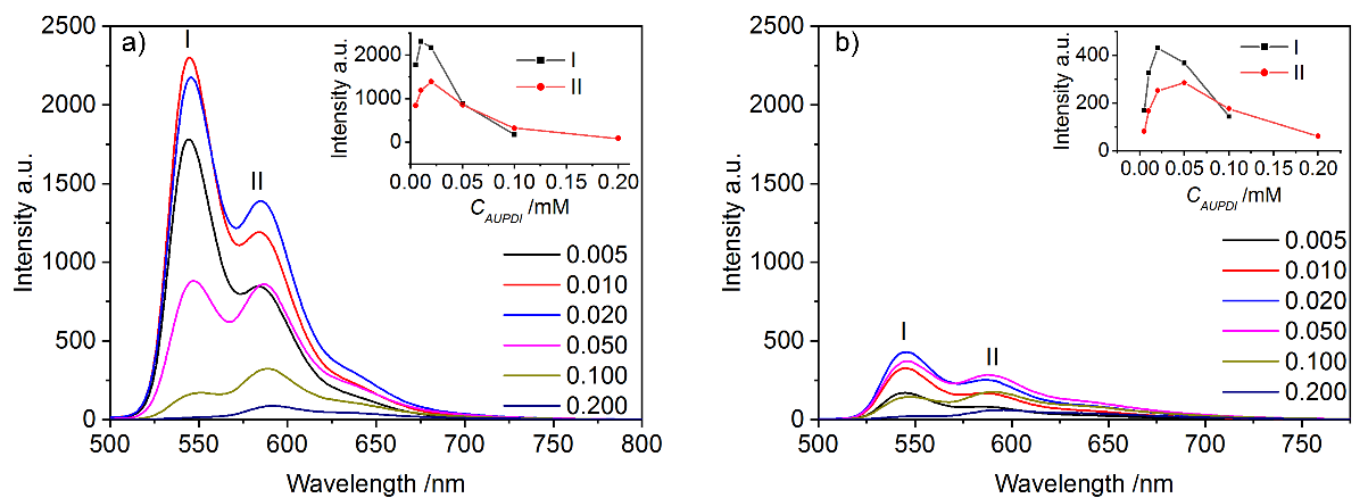

Figure S8. Fluorescence spectra of AUPDI as a function of concentration in chloroform (a) and xylene (b); the insets represent the intensity of the two peaks with varied concentration. 


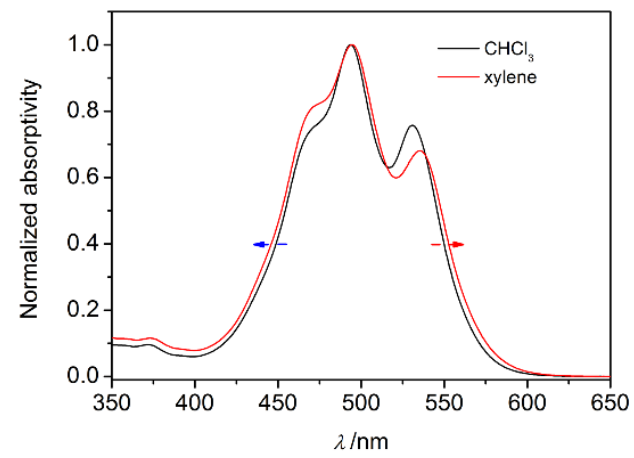

Figure S9. Normalized absorptivity of AUPDI in chloroform and p-xylene $(\mathrm{c}=0.200$ $\mathrm{mM})$.
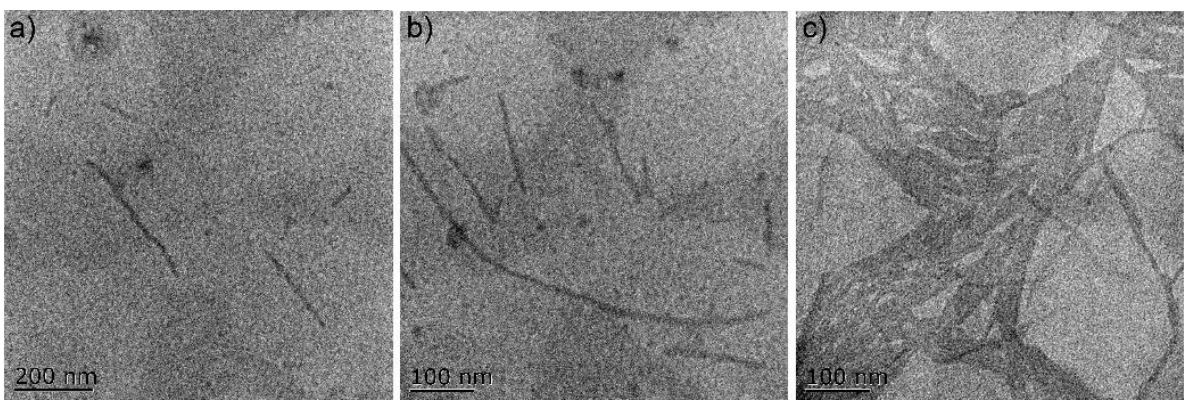

Figure S10. TEM images of the AUPDI helical nanofibrils in chloroform $(a, b)$ and pxylene (c) at: (a) $0.050 \mathrm{mM}$, (b) $0.080 \mathrm{mM}$, (c) $0.200 \mathrm{mM}$, scale bars are $100 \mathrm{~nm}$ and 200 nm. 


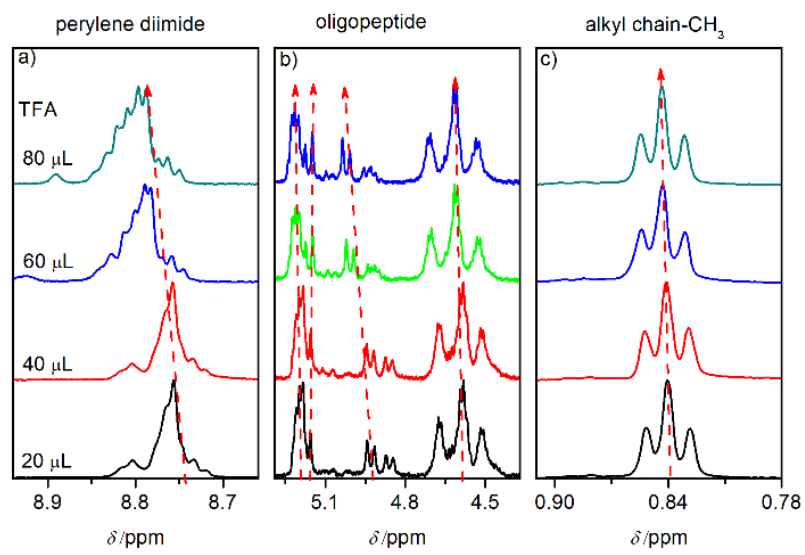

Figure S11. NMR signal of AUPDI in chloroform-d with varied TFA-d content: a) protons on perylene diimide ring, b) $\mathrm{C}-\mathrm{H}$ protons of oligopeptide backbone, c) the protons of the terminal methyl on the alkyl chain.
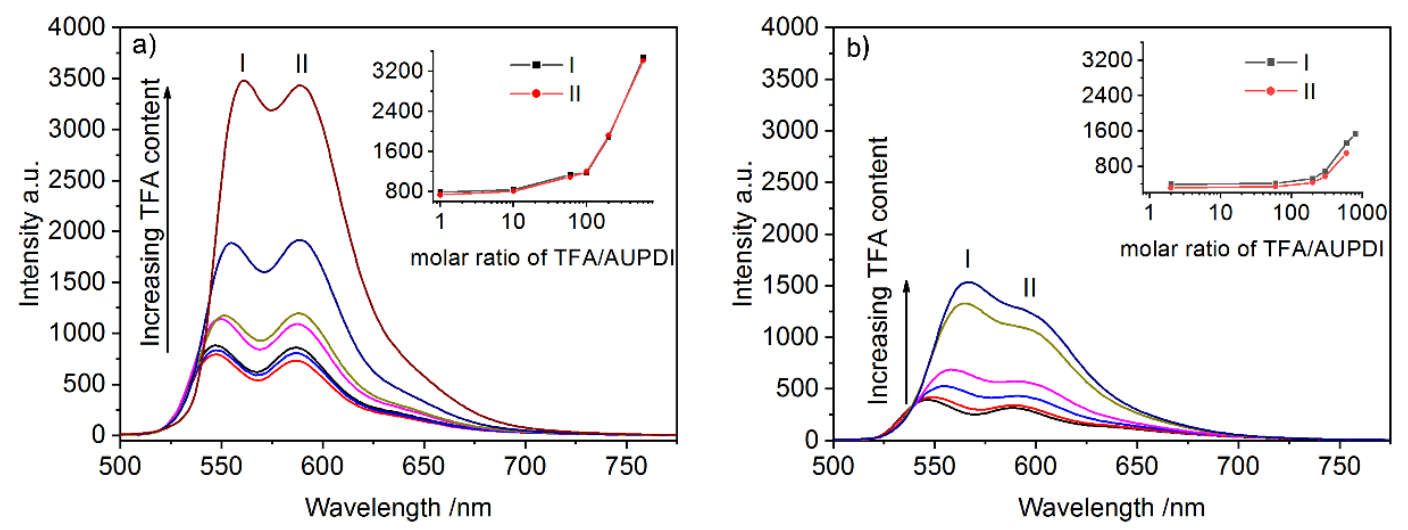

Figure S12. Fluorescence spectra of AUPDI in chloroform (a) and xylene (b) with varied molar ratio of TFA to AUPDI; the insets represent the intensity of the two peaks with increasing TA ratio. 
Table S1 The simulated parameters of SAXS results in Figure 6.

\begin{tabular}{ccccc}
\hline & $\mathrm{q}^{*} / \mathrm{nm}^{-1}$ & $\mathrm{~d} / \mathrm{nm}^{1}$ & fwhm & Adj-R \\
\hline chloroform & 1.143 & 5.50 & 0.040 & 0.996 \\
chloroform+TFA & $1.215 / 1.285$ & $5.17 / 4.89$ & $0.026 / 0.012$ & 0.995 \\
xylene & 1.112 & 5.65 & 0.041 & 0.987 \\
xylene+TFA & $1.113 / 1.268$ & $5.64 / 4.95$ & $0.038 / 0.012$ & 0.998 \\
\hline
\end{tabular}

${ }^{1} d=2 \pi / q, q$ is the scattering wave vector, $\pi$ is set to 6.28 within the calculations. 